\title{
Is social exposure to obesity associated with weight status misperception? Assessing Australians ability to identify overweight and obesity
}

\author{
C. A. Opie ${ }^{1,2^{*}}$, K. Glenister ${ }^{1}$ and J. Wright ${ }^{1}$
}

\begin{abstract}
Introduction: Overweight and obesity prevalence has increased significantly over the past two decades, currently impacting greater than $60 \%$ of Australians. It is unclear if a social perception of a healthy weight has been obscured by the increase in prevalence and thus has become inconsistent with the medical definitions.

Methods: An electronic questionnaire was distributed via email and social media using the authors' informal networks. Australian adults were eligible to participate. Participants were asked to categorise their own body size using medically accepted words and previously published silhouettes, before identifying underweight, healthy weight, overweight or obesity in a series ofsilhouettes.

Results: Eight hundred six questionnaires were completed, a majority of participants had attained a high level of education and were employed female health professionals. Under half the studied population had a Body Mass Index (BMI) corresponding to overweight or obese categories $(n=349,47 \%)$. Accuracy in self-perceived weight status using medicalised words was higher among respondents with BMI corresponding to the healthy weight category $(n=311,85 \%)$ and overweight category $(n=133,74 \%)$ than for respondents with BMI corresponding to obesity $(n=79,45 \%)$ or underweight $(n=5,31 \%)$. A majority of respondents were able to accurately self-perceive their weight status using silhouettes $(n=469,70 \%)$. Females were significantly more likely to be accurate in their self-perception than males, using both medicalised words $(p=<0.001)$ and silhouettes $(p=0.045)$. Respondents with a BMI corresponding to the obese category were significantly more likely to be accurate with weight status self-perception using silhouettes than words ( $87 \%$ versus $46 \%$ respectively, $p=<0.001$ ). Less than half (41\%) of respondents accurately perceived silhouettes corresponding to an overweight BMI and less than one in ten respondents (9\%) accurately perceived the lower limit of the silhouettes corresponding to an obese BMI.

Conclusions: Repondents were challenged to accurately perceive silhouettes corresponding to an obese BMI in themselves and others. Weight status misperception was more likely to exist among those with a BMI less than 18.5 or 30 or more (underweight BMI and obese BMI). Accuracy decreased as BMI increased. Respondents with a BMI in the obese category were significantly more likely to accurately self-perceive their weight status using silhouettes than medicalised words. Silhouettes may act as an effective visual cue in initiating weight related discussions.
\end{abstract}

Keywords: Obesity, Overweight, Body mass index, Waist circumference, Social conditioning, Weight perceptions

\footnotetext{
* Correspondence: loulata3@gmail.com

${ }^{1}$ Department of Rural Health, The University of Melbourne, Graham Street,

Shepparton, Victoria 3630, Australia

${ }^{2}$ Echuca Regional Health, Research Department, 226 Service Street, Echuca,

Victoria 3564, Australia
}

(c) The Author(s). 2019 Open Access This article is distributed under the terms of the Creative Commons Attribution 4.0 International License (http://creativecommons.org/licenses/by/4.0/), which permits unrestricted use, distribution, and reproduction in any medium, provided you give appropriate credit to the original author(s) and the source, provide a link to the Creative Commons license, and indicate if changes were made. The Creative Commons Public Domain Dedication waiver (http://creativecommons.org/publicdomain/zero/1.0/) applies to the data made available in this article, unless otherwise stated. 


\section{Introduction}

Australia is experiencing an obesity epidemic, directly and indirectly costing the economy a conservative estimate of $\$ 8.6$ billion (2014/15), a figure forecast to reach $\$ 87.7$ billion by 2025 if not addressed [1]. In 2014-15, almost two out of three Australians (11.2 million people, $63 \%$ ) were overweight or obese, a significant increase since 1995 (56\%) [2]. Unhealthy weight increases the risk of chronic conditions including some forms of cancer, eating disorders, poor mental health, osteoarthritis, Type 2 Diabetes Mellitus (T2DM) and Cardiovascular Disease (CVD) $[3,4]$. Overweight and obesity prevalence is even greater in rural populations (69\%) [5].

Early intervention and secondary prevention of an unhealthy weight relies on Australian primary healthcare professionals routinely calculating body mass predictors (height and weight to calculate a Body Mass Index (BMI) and waist circumference), on every adult $[4,6]$. Criticisms have been raised regarding the use of BMI due to the inability to assess proportions of muscle mass compared with fat mass [7], though when combined with waist circumference, it is considered a strong predictor of health risk [8]. Eighty seven percent of Australians access their General Practitioner (GP) at least once a year [9], emphasising that GPs are well poised to identify an unhealthy weight and treat accordingly $[4,8]$. Furthermore, patients expect their GP to initiate a weight related discussion when required [10]. Yet, contemporary evidence suggests that less than a quarter of Australian adults $(22 \%)$ have a BMI documented in their GP medical record and even fewer have a waist measurement recorded [11]. Morevoer, obesity is the individual problem managed in a patient encounter in $0.8 \%$ of GP consultations (0.8\%) [6].

An unhealthy weight is however, a risk factor for many of the most common presenting conditions in general practice including musculoskeletal encounters $(12 \%$ of GP activity), circulatory encounters $(10 \%)$ or endocrine and metabolic encounters (9\%) and therefore may provide a supplementary opportunity for brief intervention [6]. Although average appointment times are brief (approximately $15 \mathrm{~min}$ ) [6], the majority of GP encounters involve a single issue and it is important to highlight the contribution of weight to relevant presenting complaints. Any opportunity for brief intervention (30 s) to motivate weight loss is known to be helpful and acceptable to over $99 \%$ of patients with obesity, even when the encounter is unrelated to weight [12]. Incidently, Ling and colleagues report that for adolescents, health professional recommendations are more likely to influence weight loss attempts than parents [13].

In a society where more people exhibit an unhealthy weight than a healthy weight, social perception of a healthy weight is at risk of becoming obscured [14], leading to people with overweight and/or obesity perceiving their weight as healthy. If people with overweight and/or obesity do not recognise their weight as a risk factor for chronic conditions, public health messages will not resonate. Binkin et al. (2013) reported in their obesity perception study among mothers and children that 'what is common has a greater likelihood of being perceived as normal' [15]. Misperception develops as early as 9 years of age and is heavily influenced by peer and familial weight [16]. Among adults, males are reportedly more likely to misperceive an overweight or obese weight status than females, regardless of cultural background [17]. Any misperception among society may be cause for concern, considering that it is believed that an individual attempt to lose weight is mainly driven by a self-perception of being "too heavy", regardless of accuracy [13]. Health professionals are not immune to weight status misperception $[10,14,18,19]$ hence, poor identification of an unhealthy weight by health professionals may mislead or contribute to misperception.

There is limited evidence investigating whether adult Australians may be becoming obscured in their perceptions of weight status by the increase in prevalence of overweight and obesity. The aim of this study was to assess whether Australians, including health professionals are challenged to identify overweight or obesity and whether rural residence, body size or gender impacts identification.

\section{Method}

\section{Study aim}

To assess people's ability to identify overweight and obesity.

\section{Study design}

An electronic questionnaire was developed for this study, utilising silhouette images previously published [20] (Additional file 1). The questionnaire was pilot tested (self-administered, paper based) for clarity of questions and acceptability $(n=12)$ before being distributed as an electronic survey. Respondents were asked a series of demographic questions (age, gender, postcode, educational attainment, employment status and whether they were a health professional (HP). Respondents were asked to report their height and weight before matching their own weight with medicalised words (underweight; healthy weight; overweight; obese). Respondents were asked to match their own weight with gender specific body figure silhouettes [20] before matching each medicalised word with a silhouette. These silhouettes were developed by Harris et al. [20] as a novel pictorial method for assessing perception of weight status, and have been assessed for validity and test-retest reliability [20]. This study utilised these silhouettes to assess 
perception of weight status in both self and others, with the aim of identifying demographic variables associated with perception of weight status.

\section{Participants}

Adults (aged 18 years and over) residing in Australia were eligible to participate.

\section{Recruitment}

Primary dissemination of the online survey was through the researchers' informal networks including their rural health service and university communities, via email and social media. Responders were asked to further disseminate the survey through their professional and personal networks as a snowballing recruitment strategy. Consent to participate was requested at the beginning of the online survey, unless the participant selected 'yes', they were unable to enter the survey. Data were collected and managed using RedCap electronic data capture tools [21] hosted at the University of Melbourne. RedCap (Research Electronic Data Capture, Vanderbuilt University, United States) is a secure, web-based application designed to support data capture for research studies, providing: 1) an intuitive interface for validated data entry; 2) audit trails for tracking data manipulation and export procedures; 3 ) automated export procedures for seamless data downloads to common statistical packages; and 4) procedures for importing data from external sources [21].

\section{Analysis}

Self-reported height and weight data was used to calculate BMI according to the internationally defined formula: weight (kilograms) divided by the square of height (centimetres), before being categorised into underweight (BMI < 18.5); healthy weight (BMI 18.5-24.9); overweight (BMI 25-29.9); obese (BMI $\geq 30$ ) [22]. Postcodes were categorised according to the Modified Monash Model into major cities (MMM1) and MMM2-7 (regional and remote) [23]. Data were analysed using Statistical Package for Social Sciences (SPSS) Version 22 for descriptive statistics and cross-tabulations between categories. Direct logistic regression was used to assess the impact of independent variables (age, sex, BMI, HP/non $\mathrm{HP}$ and city/rural residence) on accuracy of weight perception. Specifically, four separate logistic regression analyses were completed for the dependent variables of accurate perception of BMI category in self using words, accurate perception of BMI category in self using silhouettes, accurate perception of overweight in others (silhouettes) and accurate perception of obesity in others (silhouettes).

\section{Funding}

Nil specific funding was sought for this study. All authors were employed by the The University of Melbourne, Department of Rural Health which is funded to conduct health research by the Commonwealth of Australia Rural Health Multidisciplinary Training Program.

\section{Results}

A total of 806 questionnaires were completed, a majority of responders were female $(n=656,85.1 \%)$, over half were HPs $(n=379,50.8 \%)$ and of those that provided a postcode $(n=770,95.5 \%), 64.4 \%,(n=519)$ lived in a regional/remote community and $32.6 \%(n=251)$ resided in a major city. On average participants were $41.0 \pm 12.5$ years old, a high rate of tertiary education and employment status is evident (Table 1).

\section{Body mass index}

Height and weight was self-reported by 747 (92.7\%) respondents; hence BMI was able to be calculated in the majority of cases (Table 2). Overweight prevalence was $23.7 \%(n=177)$ and obesity prevalence was $23.0 \%(n=$ $172)$ in this cohort. The prevalence of obesity was similar among regional/remote respondents $(n=117,24.1 \%)$ and respondents from major cities $23.0 \%(n=56,23.0 \%$, $p=0.736$ ).

\section{Self-perception of weight status using medicalised words} Overall, $72 \%(n=528)$ of respondents correctly identified the category that matched their BMI as calculated from self-reported height and weight. Accuracy was greatest for respondents with a BMI corresponding with the healthy weight category $(n=311,85 \%)$ and overweight category $(n=133,74 \%)$ and lower for respondents with a BMI corresponding with the underweight category $(n=$

Table 1 Education and Employment characteristics of the sample

\begin{tabular}{ll}
\hline Variable & $\mathrm{n}(\%)$ \\
\hline Education Status & $15(2.0 \%)$ \\
Partial Secondary & $53(6.9 \%)$ \\
Secondary & $108(14.1 \%)$ \\
Technical and Further Education (TAFE) & $590(77.0 \%)$ \\
Tertiary & \\
Employment Status & $401(49.8 \%)$ \\
Full Time & $290(36.0 \%)$ \\
Part Time & $8(1.0 \%)$ \\
Unemployed & $85(10.5 \%)$ \\
Student & $5(0.6 \%)$ \\
Retired & $6(0.7 \%)$ \\
Not in Labour Force
\end{tabular}


Table 2 Self-reported Body Mass Index

\begin{tabular}{lllll}
\hline & $\begin{array}{l}\text { Male } \\
\mathrm{n}(\%)\end{array}$ & $\begin{array}{l}\text { Female } \\
\mathrm{n}(\%)\end{array}$ & $\begin{array}{l}\text { Sample } \\
\mathrm{n}(\%)\end{array}$ & p (proportion males vs females X') \\
\hline Underweight (BMI < 18.5) & $1(0.9 \%)$ & $15(2.4 \%)$ & $16(2.2 \%)$ & 0.528 \\
Healthy weight (BMI 18.5-24.9) & $53(48.6 \%)$ & $312(50.2 \%)$ & $365(50.0 \%)$ & 0.755 \\
Overweight (BMI 25-29.9) & $32(29.4 \%)$ & $145(23.3 \%)$ & $177(24.2 \%)$ & 0.177 \\
Obese (BMI $\geq 30)$ & $23(21.1 \%)$ & $149(24.0 \%)$ & $172(23.6 \%)$ & 0.325 \\
\hline
\end{tabular}

$5,31 \%)$ and obese category $(n=79,45 \%)$ (Table 3$)$. Females were more commonly able to correctly categorise their own body size than males ( $73 \%$ vs $64 \%$ respectively, $p<0.001)$.

\section{Self-perception of weight status using silhouettes}

Overall, $70.2 \%(n=469)$ of respondents accurately perceived the silhouette that matched their BMI. Females ( $n=407,72 \%$ ) were more likely to accurately perceive their silhouette than males (72\% vs $61 \%$ respectively, $p=$ $0.045)$. A significantly greater proportion of respondents with a BMI corresponding with the obese category selfperceived their weight status accurately using the silhouettes than the medically accepted words (87\% vs $46 \%$, $p<0.001$ ) (Table 3).

\section{Weight status perception in others}

The majority of respondents accurately perceived the underweight silhouettes $(n=557,69.1 \%)$ and healthy weight silhouettes $(n=589,73.1 \%)$. Less than half of respondents accurately identified the overweight silhouette $(283,41 \%)$ and less than one out of ten respondents accurately perceived the lower limit of obesity within the silhouettes (65, 9.3\%) (Fig. 1).

The ability to accurately perceive the lower limit of obesity did not differ significantly between males and females $(7.1 \%$ vs $8.7 \%, p=0.587)$, HPs and non-HPs $(9.2 \%$ vs $7.6 \%, p=0.430)$, respondents from regional $/$ remote areas and cities $(9.4 \%$ vs $6.4 \%, p=0.151)$ or respondents with a BMI corresponding to obesity or not $(8.6 \%$ vs $8.6 \%, p=0.979)$. Four separate logistic regression analyses were undertaken (Table 4):

a) Dependent variable: accurate perception of BMI category in self using words. As BMI increased accuracy decreased. Males were less accurate in perception of their own BMI category (odds ratio 0.41) than females.

Table 3 Summary of self-perception of weight status using medicalised words versus silhouettes

\begin{tabular}{|c|c|c|c|c|c|c|c|c|c|}
\hline & \multicolumn{4}{|c|}{ Medicalised Words } & \multicolumn{4}{|l|}{ Silhouettes } & \multirow{2}{*}{$\begin{array}{l}\text { Words vs } \\
\text { Silhouettes } \\
p \text { value }\end{array}$} \\
\hline & $\begin{array}{l}\text { Matched } \\
\mathrm{n}(\%)\end{array}$ & $\begin{array}{l}\text { Underestimated } \\
\mathrm{n}(\%)\end{array}$ & $\begin{array}{l}\text { Overestimated } \\
\mathrm{n}(\%)\end{array}$ & $p$ value & $\begin{array}{l}\text { Matched } \\
\mathrm{n}(\%)\end{array}$ & $\begin{array}{l}\text { Underestimated } \\
\mathrm{n}(\%)\end{array}$ & $\begin{array}{l}\text { Overestimated } \\
\mathrm{n}(\%)\end{array}$ & $p$ value & \\
\hline Overall & $\begin{array}{l}528 \\
(71.9)\end{array}$ & $148(20.2)$ & $58(7.9)$ & - & $469(70.2)$ & $84(12.5)$ & $116(17.3)$ & - & 0.450 \\
\hline Male & $70(64.2)$ & $35(32.1)$ & $4(3.7)$ & $<0.001$ & $60(60.6)$ & $19(19.2)$ & $20(20.2)$ & 0.045 & 0.591 \\
\hline Female & $\begin{array}{l}455 \\
(73.4)\end{array}$ & $111(17.9)$ & $54(8.7)$ & & $407(72.0)$ & $65(11.5)$ & $93(16.3)$ & & 0.602 \\
\hline $\begin{array}{l}\text { Regional/ } \\
\text { Remote }\end{array}$ & $\begin{array}{l}342 \\
(70.4)\end{array}$ & $102(21.0)$ & $42(8.7)$ & 0.369 & $\begin{array}{l}313 . \\
(69.6)\end{array}$ & $51(11.3)$ & $86(19.2)$ & 0.110 & 0.712 \\
\hline Major City & $\begin{array}{l}184 \\
(75.4)\end{array}$ & $44(18.0)$ & $16(6.6)$ & & $155(72.4)$ & $31(14.5)$ & $28(13.0)$ & & 0.468 \\
\hline $\mathrm{HP}$ & $\begin{array}{l}264 \\
(73.7)\end{array}$ & $66(18.4)$ & $28(7.8)$ & 0.552 & 235 (71.6) & $39(11.9)$ & $54(16.3)$ & 0.763 & 0.538 \\
\hline Non-HP & $\begin{array}{l}248 \\
(70.9)\end{array}$ & $76(21.7)$ & $26(7.4)$ & & $223(69.5)$ & $44(13.7)$ & $54(16.8)$ & & 0.695 \\
\hline Underweight & $5(31.3)$ & 0 & $11(68.8)$ & & $8(50)$ & 0 & $8(50.0)$ & $<$ & 0.280 \\
\hline Healthy weight & $\begin{array}{l}311 \\
(85.2)\end{array}$ & $10(2.7)$ & $44(12.1)$ & $0.001^{a}$ & $258(79.1)$ & $23(7.1)$ & 45 (13.8) & $0.001^{\mathrm{a}}$ & 0.037 \\
\hline Overweight & $\begin{array}{l}133 \\
(74.3)\end{array}$ & $43(24.0)$ & $3(1.7)$ & & $60(37.3)$ & $39(24.2)$ & $62(38.5)$ & & $<0.001$ \\
\hline Obese & 79 (45.5) & 95 (54.6) & 0 & & $143(86.7)$ & $22(13.3)$ & 0 & & $<0.001$ \\
\hline
\end{tabular}



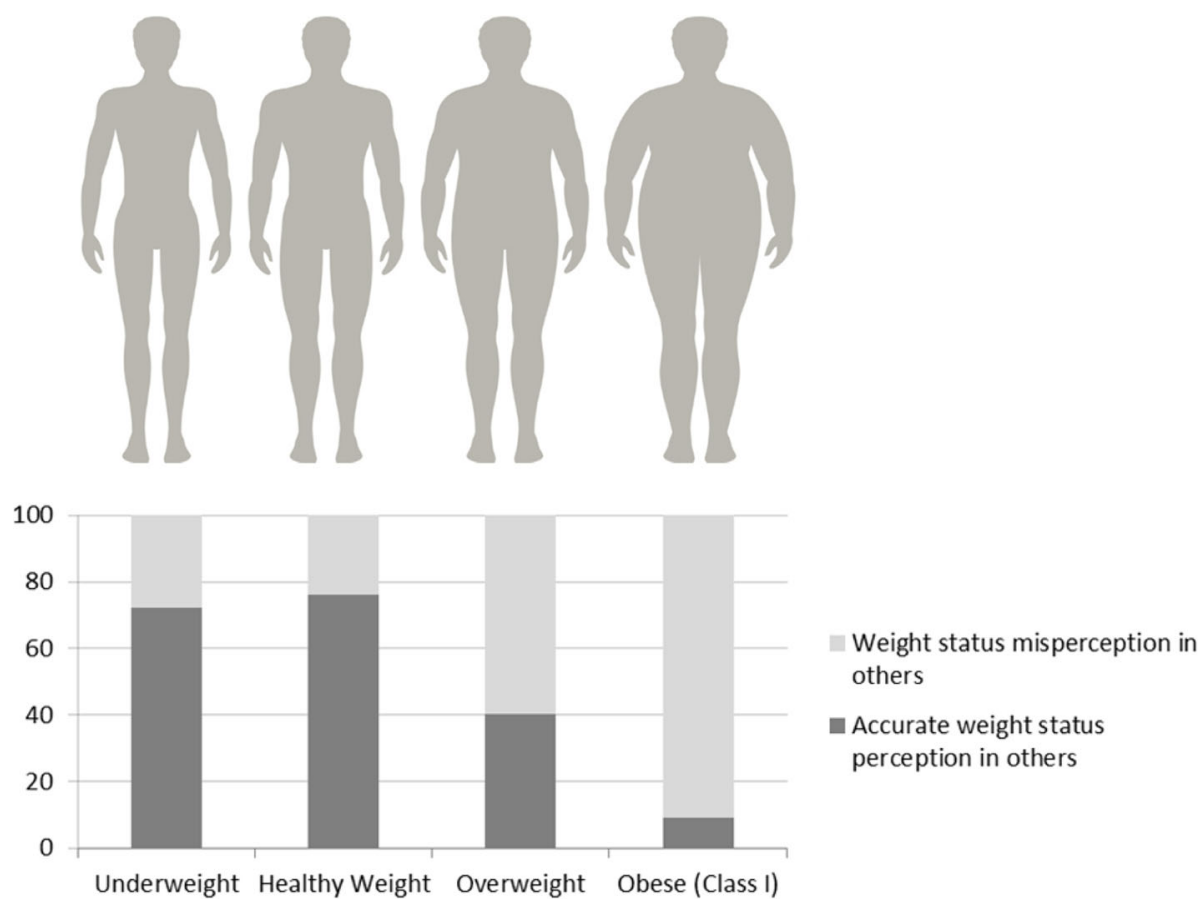

Fig. 1 Perception of weight status in others using silhouettes (image sourced from iStock)

b) Dependent variable: accurate perception of BMI category in self using silhouettes. As BMI increased, accurate perception of own BMI category using silhouettes also increased. As age increased, accurate perception of own BMI category decreased.

c) Dependent variable: accurate perception of overweight in others using silhouettes. Males were less accurate (odds ratio 0.46) than females in perception of overweight in others. As BMI increased perception of overweight in others decreased.

d) Dependent variable: accurate perception of obesity in others using silhouettes. None of the independent variables included were significantly associated with accurate perception of silhouettes corresponding to obesity.

Females were significantly more accurate in selfperception of weight status than males using words.

Table 4 Accurate perception of weight status, logistic regression (odds ratio, 95\% Cl, p value)

\begin{tabular}{|c|c|c|c|c|}
\hline \multirow[b]{2}{*}{ Independent variables: } & \multirow{2}{*}{$\begin{array}{l}\text { Words } \\
\text { Perception of weight status } \\
\text { (self) }\end{array}$} & \multicolumn{3}{|l|}{ Silhouettes } \\
\hline & & $\begin{array}{l}\text { Perception of weight status } \\
\text { (self) }\end{array}$ & $\begin{array}{l}\text { Perception of overweight in } \\
\text { others }\end{array}$ & $\begin{array}{l}\text { Perception of obesity in } \\
\text { others }\end{array}$ \\
\hline \multirow[t]{2}{*}{ Sex $($ male $=1$, female $=0)$} & 0.41 & 0.74 & 0.46 & 0.84 \\
\hline & $0.25-0.66 p<0.001$ & $0.41-1.35 p=0.327$ & $0.29-0.74 p=0.001$ & $0.38-1.82 p=0.653$ \\
\hline \multirow[t]{2}{*}{ BMI (continuous) } & 0.91 & 1.06 & 0.96 & 1.01 \\
\hline & $0.89-0.94 p<0.001$ & $1.02-1.10 p=0.006$ & $0.94-0.99 p=0.002$ & $0.97-1.05 p=0.424$ \\
\hline \multirow[t]{2}{*}{ Age (continuous) } & 1.00 & 0.96 & 0.99 & 0.99 \\
\hline & $0.98-1.01 p=0.758$ & $0.95-0.98 p<0.001$ & $0.98-1.01 p=0.304$ & $0.97-1.01 p=0.424$ \\
\hline \multirow{2}{*}{$\begin{array}{l}\text { Health professional (yes }=1 \\
\text { no }=0 \text { ) }\end{array}$} & 1.03 & 1.18 & 0.81 & 1.15 \\
\hline & $0.68-1.56 p=0.879$ & $0.74-1.67 p=0.482$ & $0.59-1.11 p=0.190$ & $0.67-1.99 p=0.613$ \\
\hline \multirow[t]{2}{*}{ City (yes $=1$, no $=0$ ) } & 1.23 & 1.24 & 0.89 & 0.61 \\
\hline & $0.78-1.95 p=0.373$ & $0.74-1.87 p=0.428$ & $0.63-1.26 p=0.510$ & $0.32-1.15 p=0.128$ \\
\hline $\begin{array}{l}\text { Cases correctly classified by } \\
\text { model }\end{array}$ & $76.8 \%$ & $81.9 \%$ & $61.9 \%$ & $91.3 \%$ \\
\hline
\end{tabular}


BMI appeared to influence accuracy of weight status in self and identification of a silhouette corresponding with an overweight BMI, though the association was weak. Females were significantly more accurate for perception of an overweight BMI category in others, than males. None of these variables were significantly associated with accuracy of identifying a silhouette corresponding with an obese BMI.

\section{Discussion}

Overweight and obesity prevalence among self-reporting study respondents was lower than current Australian estimates (46.7\% versus $63.4 \%$ respectively) [2]. Health literacy levels may be assumed to be high, considering the sample were well educated and mostly employed health professionals. Yet, a majority of respondents were unable to identify the lower limit of a BMI corresponding with the obese category, in both themselves and others. In fact, as weight status increased, accuracy decreased. The national obesity epidemic, where almost two out of three people are either overweight or obese [2] may have engendered a society that no longer recognises the threshold of unhealthy weight.

Men in particular lacked accuracy in self-perception of weight status using medicalised words (underweight; healthy weight; overweight; obese) and were more likely to underestimate their weight status using silhouettes than females. Men's inability to accurately perceive their weight status using either medicalised words or visual cues has some support in the literature. A study from the United States (US), found that men with an overweight weight BMI perceived that they had a BMI corresponding with an underweight or a healthy weight status [24].

Weight status misperception using medicalised terminology was greatest among respondents corresponding with each end of the weight staus index (underweight and obese), regardless of gender. People at greatest risk of chronic ill health due to their weight therefore appear to have the poorest self-perception of their weight. In their cross-sectional survey of adolescents in Hong Kong, Cheung et al. (2007) found that females in particular are motivated to adopt weight control behaviours if they perceive themselves to be overweight [25]. Assuming active weight control behaviours resulting from weight self-perception in adolescents continue into adulthood, consistent attempts to measure weight predictors and discuss the effects of weight upon health is likely to be beneficial throughout life.

Respondents with a BMI corresponding with the obese category were however, more accurate in self-perception of weight status using silhouettes than medicalised words, a finding consistent with Harris et al. 2008. Self- perceiving an unhealthy weight is known to be most problematic among people with a BMI equating to overweight or obesity [20,26]. Surprisingly however, regardless of weight status, almost nine out of ten respondents misperceived the lower limit of obesity using silhouettes, a finding that suggests that increasing prevalence of obesity and social exposure may indeed be influencing social perception of obesity [18].

Healthy weight people are now a minority in Australian society potentially influencing the perception of both HPs and the general population alike. HPs and non-HP respondents equally misperceived the lower limit of obesity using either medicalised terminology or silhouettes. Wong and colleagues (2016) found that medically trained professionals and the general public were mutually inaccurate in their perceptions of people identified as overweight or obese [19]. A recent US study found that parents underestimated the weight of their children with an overweight or obese BMI (96 and 72\% respectively) and this pattern appeared independent of socioeconomic/educational factors [27]. The authors attributed the findings to social and cultural beliefs and attitudes that have resulted from the high incidence of children identified as overweight or obese in contemporary society in comparison to previous generations [27]. As it appears that weight related perceptions develop early in life, weight concerns ought to be addressed as early as possible, particularly in rural areas where prevalence is greater [5].

It is important to note the identified limitations of this study. Firstly, the responding adults in the study may be subject to selection bias and findings cannot be generalised to the Australian population, though may be representative of Australians with a mid to high socioeconomic status. The online survey was primarily disseminated within regional health services where the authors are situated, presumably contributing to the high representation of English speaking females with internet access, health professionals with a higher education and regional/remote people. If the sample was more representative of the Australian population and included a higher proportion of males, people with low socioeconomic status and low educational attainment, then perception of overweight and obesity may be able to be more fully explored among people at particular risk of obesity. Secondly, results are subject to social desirability bias where it is known that people may report an inaccurate height and weight in an attempt to impress and conform with social norms [28], though underestimation of weight and overestimation of height is generally insufficient to alter BMI category [29]. Respondents were additionaly asked to self-report their waist circumference as a secondary predictor of health risk [8], in an attempt to mitigate bias, particularly as it is known that BMI 
alone fails to differentiate muscle mass and fat mass [7]. It is also known that people poorly monitor their weight, particularly men, a contributing factor in self-reporting bias [28]. Web-based testing however, has been found to moderate socially desirable responses 1.51 times greater than comparable pen-and-pencil questionnaires when seeking a disclosure of sensitive issues, due largely to the anonymous nature of inquiry [30].

\section{Conclusion}

People from cities, rural areas, health professionals and non-health professionals are equally challenged to accurately perceive a BMI corresponding with obesity in themselves and others. Weight status misperception was more likely to exist among those with a BMI less than 18.5 or 30 or more (underweight and obese). Largely, as weight status increased, accurate perception decreased. Visual cues however, appear to improve accuracy, given respondent corresponding with an obese BMI were significantly more likely to accurately self-perceive their weight status using silhouettes than medicalised words. Silhouettes therefore may act as an effective visual cue in initiating weight related discussions.

\section{Additional file}

Additional file 1: Perceptions of body weight and preferred language (PDF $53 \mathrm{~kb}$ )

\section{Abbreviations}

BMI: Body Mass Index; CVD: Cardiovascular Disease; GP: General Practitioner; HP: Health Professional; MMM: Modified Monash Model; T2DM: Type 2 Diabetes Mellitus

\section{Acknowledgements}

Not applicable.

\section{Authors' contributions}

KG primarily designed the questionnaire. Questionnaire checked for clinical appropriateness by $\mathrm{CO}$, with minor additions made. $\mathrm{KG}$ and $\mathrm{CO}$ distributed the questionnaire. KG statistically analysed the data before being discussed for meaning with $\mathrm{CO}$. CO wrote the first draft of the manuscript, KG and JW contributed to subsequent drafts. All authors read and approved the final manuscript.

\section{Funding}

All authors were employed by the The University of Melbourne, Department of Rural Health which is funded by the Commonwealth of Australia Rural Health Multidisciplinary Training Program.

\section{Availability of data and materials}

Both the original questionnaire and de-identified copies of completed questionnaires are available from the corresponding author. Data is available from the corresponding author on reasonable request.

\section{Ethics approval and consent to participate}

Approval for the research was granted by the Human Ethics Advisory Group at the University of Melbourne (Identification Number 1748731.1). Consent to participate was requested at the beginning of the online survey, unless the participant selected 'yes', they were unable to enter the survey.
Consent for publication

Not Applicable.

\section{Competing interests}

The authors declare that they have no competing interests.

Received: 29 May 2018 Accepted: 27 August 2019

Published online: 04 September 2019

\section{References}

1. Pricewaterhouse Cooper. Weighing the Cost of Obesity: A Case for Action. Australia: PwC; 2015

2. 4364.0.55.001 - National Health Survey: First Results, 2014-15 [http://www abs.gov.au/ausstats/abs@.nsf/mf/4364.0.55.001]. Accessed 31 Oct 2017.

3. Sturgiss EA, van Weel C, Ball $L$, Jansen $S$, Douglas $K$. Obesity management in Australian primary care: where has the general practitioner gone? Aust J Prim Health. 2016;22:473-6.

4. National Health and Medical Research Council. In: Australian Government, editor. Summary guide for the management of overweight and obesity in primary care. Canberra: NHMRC; 2013.

5. Australian Institute of Health and Welfare. Australia's health 2016. In: AlHW, editor. Australian health series no 15 cat no AUS 199. Canberra: Australian Government; 2016.

6. Britt H, Miller GC, Henderson J, Bayram C, Harrison C, Valenti L, Pan Y, Charles J, Pollack AJ, Wong C, Gordon J. General practice activity in Australia 2015-16. Sydney: Sydney University Press General Practice Series no 40; 2016.

7. National Health and Medical Research Council. Clinical practice guidelines for the Management of Overweight and Obesity and in adults, Adolescents and Children in Australia. Melbourne: National Health and Medical Research Council; 2013

8. Royal Australian College of General Practitioners. RACGP guidelines for preventive activities in general practice. 8th ed; 2012

9. National Health Performance Authority:: National Health Performance Authority analysis of Department of Human Services. Medicare Benefit Statistics 2012-13. 2014

10. Thapa R, Friderici J, Kleppel R, Fitzgerald J, Rothberg MB. Do physicians underrecognize obesity? South Med J. 2014:107(6):356-60.

11. Turner LR, Harris MF, Mazza D. Obesity management in general practice: does current practice match guideline recommendations? Med J Aust. 2015; 202(7):370-2.

12. Aveyard P, Lewis A, Tearne S, Hood K, Christian-Brown A, Adab P, Begh R, Jolly K, Daley A, Farley A, et al. Screening and brief intervention for obesity in primary care: a parallel, two-arm, randomised trial. Lancet. 2016; 388(10059):2492-500.

13. Ling J, Stommel M, Choi SH. Attempts to lose weight among US children: importance of weight perceptions from self, parents, and health professionals. Obesity (Silver Spring). 2018;26(3):597-605.

14. Robinson E. Overweight but unseen: a review of the underestimation of weight status and a visual normalization theory. Obes Rev. 2017;18(10): 1200-9.

15. Binkin N, Spinelli A, Baglio G, Lamberti A. What is common becomes normal: the effect of obesity prevalence on maternal perception. Nutr Metab Cardiovasc Dis. 2013;23(5):410-6.

16. Maximova K, McGrath JJ, Barnett T, O'Loughlin J, Paradis G, Lambert M. Do you see what I see? Weight status misperception and exposure to obesity among children and adolescents. Int J Obes. 2008;32:1008-15.

17. Wardle J, Haase AM, Steptoe A. Body image and weight control in young adults: international comparisons in university students from 22 countries. Int J Obes. 2006:30(4):644-51.

18. Keightley J, Chur-Hansen A, Princi R, Wittert GA. Perceptions of obesity in self and others. Obes Res Clin Pract. 2011;5:e341-9.

19. Wong C, Harrison C, Bayram C, Miller G. Assessing patients' and GPs' ability to recognise overweight and obesity. Aust N Z J Public Health. 2016;40(6): $513-7$.

20. Harris CV, Bradlyn AS, Coffman J, Gunel E, Cottrell L. BMl-based body size guides for women and men: development and validation of a novel pictorial method to assess weight-related concepts. Int J Obes. 2008;32(2):336-42.

21. Harris PA, Taylor R, Thielke R, Payne J, Gonzalez N, Conde JG. Research electronic data capture (REDCap)--a metadata-driven methodology and workflow process for providing translational research informatics support. J Biomed Inform. 2009;42(2):377-81. 
22. World Health Organisation. Obesity: preventing and managing the global epidemic. Geneva: World Health Organisation (WHO); 2000. p. 252.

23. Modified Monash Model. [http://www.health.gov.au/internet/main/ publishing.nsf/content/modified-monash-model]. Accessed 08 Oct 2017.

24. Chang WW, Christakis NA. Self-perception of weight appropriateness in the United States. Am J Prev Med. 2003;24(4):332-9.

25. Cheung PCH, Ip PLS, Lam ST, Bibby H. A study on body weight perception and weight control Behaviours among adolescents in Hong Kong. Hong Kong Med J. 2007;13(1):16-21.

26. Paul TK, Sciacca RR, Bier M, Rodriguez J, Song S, Giardina EG. Size misperception among overweight and obese families. J Gen Intern Med. 2015;30(1):43-50.

27. Howe CJ, Alexander G, Stevenson J. Parents' underestimations of child weight: implications for obesity prevention. J Pediatr Nurs. 2017;37:57-61.

28. Burke MA, Carman KG. You can be too thin (but not too tall): social desirability bias in self-reports of weight and height. Econ Hum Biol. 2017; 27(Pt A:198-222.

29. Pursey K, Burrows TL, Stanwell P, Collins CE. How accurate is web-based self-reported height, weight, and body mass index in young adults? J Med Internet Res. 2014;16(1):e4.

30. Gnambs T, Kaspar K. Disclosure of sensitive behaviors across selfadministered survey modes: a meta-analysis. Behav Res Methods. 2015;47(4): 1237-59.

\section{Publisher's Note}

Springer Nature remains neutral with regard to jurisdictional claims in published maps and institutional affiliations.

Ready to submit your research? Choose BMC and benefit from:

- fast, convenient online submission

- thorough peer review by experienced researchers in your field

- rapid publication on acceptance

- support for research data, including large and complex data types

- gold Open Access which fosters wider collaboration and increased citations

- maximum visibility for your research: over $100 \mathrm{M}$ website views per year

At BMC, research is always in progress.

Learn more biomedcentral.com/submissions 